\title{
Article \\ The Optimization of Mix Proportion Design for SCC: Experimental Study and Grey Relational Analysis
}

\author{
Xinxin Ding ${ }^{1,2, *}$, Mingshuang Zhao ${ }^{1,2}$, Xue Qiu ${ }^{1}$, Yupu Wang ${ }^{1}$ and Yijie Ru ${ }^{1}$ \\ 1 International Joint Research Lab for Eco-Building Materials and Engineering of Henan, School of Civil \\ Engineering and Communications, North China University of Water Resources and Electric Power, \\ Zhengzhou 450045, China; zhaomingshuang@ncwu.edu.cn (M.Z.); xueqiu@stu.ncwu.edu.cn (X.Q.); \\ yupuwang@stu.ncwu.edu.cn (Y.W.); yijieru@stu.ncwu.edu.cn (Y.R.) \\ 2 Collaborative Innovation Center for Efficient Utilization of Water Resources, North China University of Water \\ Resources and Electric Power, Zhengzhou 450045, China \\ * Correspondence: dingxinxin@ncwu.edu.cn
}

Citation: Ding, X.; Zhao, M.; Qiu, X.; Wang, Y.; Ru, Y. The Optimization of Mix Proportion Design for SCC: Experimental Study and Grey Relational Analysis. Materials 2022, 15, 1305. https://doi.org/10.3390/ ma15041305

Academic Editor: Dario

De Domenico

Received: 20 December 2021

Accepted: 3 February 2022

Published: 10 February 2022

Publisher's Note: MDPI stays neutral with regard to jurisdictional claims in published maps and institutional affiliations.

Copyright: (C) 2022 by the authors. Licensee MDPI, Basel, Switzerland. This article is an open access article distributed under the terms and conditions of the Creative Commons Attribution (CC BY) license (https:// creativecommons.org/licenses/by/ $4.0 /)$.

\begin{abstract}
The optimization of mix proportions based on the targeted fresh and hardened performances of self-compacting concrete (SCC) is a foundation for its transition from laboratory research to industrial production. In this paper, the mix proportions of various SCC mixtures were designed by the absolute volume method with changes in the content of river sand and manufactured sand, the content of fly ash and granulated ground blast furnace slag (GGBS) and the maximum particle sizes of coarse aggregates. This experimental study was carried out to verify the workability, density and cubic compressive strength of SCC. The results show that SCC demonstrated good performance with appropriate mix proportions of manufactured sand and river sand. A hybrid effect of fly ash and GGBS appeared on the fresh performance of SCC with a constant strength, and the coarse aggregate with a smaller maximum particle size was beneficial to the workability but detrimental to the compressive strength of SCC. Finally, the optimization of the mix proportion of SCC was evaluated by grey relational analysis, in which the weight of the indicators was determined by the entropy method to improve the evaluation credibility. As a result, the optimal mix proportions of SCC were selected.
\end{abstract}

Keywords: self-compacting concrete (SCC); mix proportion design; optimization; experimental verification; the grey relational analysis

\section{Introduction}

Self-compacting concrete (SCC) is a kind of high fresh-performance concrete that fills and compacts in a given framework by its own weight without other assistance [1]. As opposed to other conventional vibrated concretes, the defining feature of SCC is its superior workability. Besides the typical requirements of setting time, cohesiveness and water retention, fresh SCC should also satisfy stricter requirements of filling ability, passing ability and segregation resistance. Furthermore, there is a closed relationship between the workability of fresh SCC and the basic mechanical properties of hardened SCC [2,3]. The correct proportioning of self-compacting concrete mixes based on the target fresh and hardened performances is a hot research point.

The mix proportion requires the segregation and settlement of fresh SCC, a large number of binder materials, a higher sand ratio and a smaller maximum particle size of coarse aggregate in order to maintain a sufficient yield value, ensure the viscosity of the fresh mixes and, ultimately, to reduce bleeding [4-7]. A traditional method to ensure the equal performance of SCC is to add mineral materials. The presence of fly ash in SCC reduces its water demand and improves its desired workability but also decreases its compressive strength [7-9]. The presence of granulated ground blast furnace slag (GGBS) in SCC improves its fresh properties as well as its continuing strength development [10,11]. A 
positive effect can be observed in SCC with both GGBS and fly ash added in an appropriate proportion and dosage [12]. The passing ability and the segregation resistance of fresh SCC reduce with increasing coarse aggregate size from $9.5 \mathrm{~mm}$ to $19 \mathrm{~mm}$, while the compressive strength of hardened SCC increases [13]. A greater amount of binder material content is required to obtain self-compacting workability for an SCC mixed with manufactured sand compared with an SCC mixed with river sand. This is due to the special morphology features of manufactured sand, such as its rough surfaces, irregular shapes, angular edges and inevitable stone powder [14-16]. The workability of fresh SCC could change with hybrid sand mixed with different contents of river sand and manufactured sand due to the changes of particle grading of the hybrid sand [17].

Numerous methods have been used to study the properties of concrete, such as laboratory tests [2,18], field monitoring [19], mathematical statistics [20], numerical analysis [21] and software simulation [22]. As the workability and strength of SCC are affected by multiple factors, it is unclear which one is the major factor. Therefore, the optimal mix proportion of SCC is difficult to obtain from original tests. This encourages research that takes concrete as a system with random, gray and fuzzy uncertain messages and tries to predict and evaluate its properties by grey relational analysis [23-25]. The grey relational analysis theory was founded in 1982 by Deng in China; it is an uncertain systematic theory dealing with a "small sample" and "poor information" [26]. As a type of system analytical technology, the basic principle of grey relational analysis is to evaluate the relationships of connections between sequences according to the geometric shape of a sequence curve. The closer the geometric shapes, the greater the correlation between the corresponding sequences and vice versa.

Based on the above statement, the optimization of the mix proportion of SCC is important to ensure its transition from laboratory research to industrial production. In this paper, an experimental verification was conducted for the mix proportion design of SCC with multiple factors, including the type and content of mineral admixtures, the type and content of sand and the maximum particle size of the coarse aggregate. The test results were evaluated by grey relational analysis to clarify the main influencing factors for both the workability and strength of SCC.

\section{Mix Proportion Design of SCC}

\subsection{Raw Materials}

Ordinary Portland cement, with a strength grade of 52.5, fly ash of class II, and ground granulated blast furnace slag (GGBS) of class S95, was used as a binder material. The detailed physical and mechanical properties of this cement are listed in Table 1, where it can be seen that it met the specification of China code GB 175 [27]. The detailed physical and mechanical properties of the fly ash and GGBS are listed in Table 2, where it can be seen that they met the specification of China code GB/T 51003 [28]. Pictures of the binder materials are presented in Figure 1.

Table 1. Physical and mechanical properties of cement.

\begin{tabular}{|c|c|c|c|c|c|c|c|c|}
\hline \multirow{2}{*}{$\begin{array}{l}\text { Fineness } \\
(45 \mu \mathrm{m}, \%)\end{array}$} & \multirow{2}{*}{$\begin{array}{l}\text { Water Requirement of } \\
\text { Normal Consistency (\%) }\end{array}$} & \multirow{2}{*}{$\begin{array}{l}\text { Density } \\
\left(\mathrm{kg} / \mathrm{m}^{3}\right)\end{array}$} & \multicolumn{2}{|c|}{ Setting Time (min) } & \multicolumn{2}{|c|}{ Compressive Strength (MPa) } & \multicolumn{2}{|c|}{ Flexural Strength (MPa) } \\
\hline & & & Initial & Final & 3 Days & 28 Days & 3 Days & 28 Days \\
\hline 8.6 & 26.6 & 3195 & 176 & 222 & 34.9 & 57.8 & 6.23 & 8.83 \\
\hline
\end{tabular}

Table 2. Physical and mechanical properties of fly ash and GGBS.

\begin{tabular}{|c|c|c|c|c|c|c|}
\hline No. & $\begin{array}{l}\text { Fineness } \\
(45 \mu \mathrm{m}, \%)\end{array}$ & $\begin{array}{l}\text { Density } \\
\left(\mathrm{kg} / \mathrm{m}^{3}\right)\end{array}$ & $\begin{array}{c}\text { Water Demand } \\
\text { Ratio (\%) }\end{array}$ & $\begin{array}{c}\text { Specific } \\
\text { Surface }\left(\mathrm{cm}^{2} / \mathrm{g}\right)\end{array}$ & $\begin{array}{l}\text { Strength Activity } \\
\text { Index (\%) }\end{array}$ & $\begin{array}{c}\text { Loss on } \\
\text { Ignition }(\%)\end{array}$ \\
\hline Fly ash & 6.9 & 2280 & 95 & 3590 & 84.3 & 5.9 \\
\hline GGBS & 1.0 & 2998 & - & 4388 & 97.6 & 2.9 \\
\hline
\end{tabular}




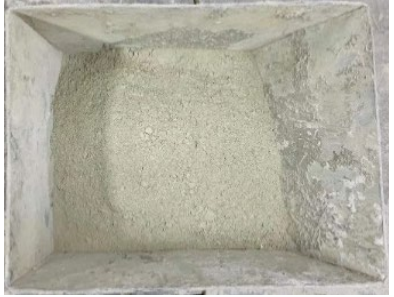

(a)

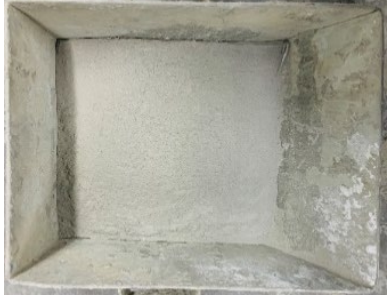

(b)

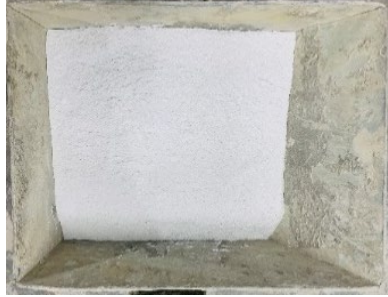

(c)

Figure 1. Pictures of binder materials: (a) cement; (b) fly ash; (c) GGBS.

Manufactured sand crushed from limestone and river sand were used as fine aggregates. Their physical and mechanical properties are listed in Table 3. Crushed limestones with maximum particle sizes of $20 \mathrm{~mm}, 16 \mathrm{~mm}$, and $10 \mathrm{~mm}$ from 1 company were used as coarse aggregates. Their physical and mechanical properties are listed in Table 4. Their particle gradations are presented in Figure 2 and are adjusted according to the principle of maximum close-packing density. The gradations of fine and coarse aggregates met the specifications of China codes GB/T 14684 and GB/T 14685 [29,30]. Pictures of the fine and coarse aggregates are presented in Figure 3.

Table 3. Physical and mechanical properties of fine aggregates.

\begin{tabular}{|c|c|c|c|c|c|c|}
\hline Type & $\begin{array}{l}\text { Fineness } \\
\text { Modulus }\end{array}$ & $\begin{array}{c}\text { Apparent Density } \\
\left(\mathrm{kg} / \mathrm{m}^{3}\right)\end{array}$ & $\begin{array}{l}\text { Closed Packing } \\
\text { Density }\left(\mathrm{kg} / \mathrm{m}^{3}\right)\end{array}$ & $\begin{array}{l}\text { Bulk Density } \\
\left(\mathrm{kg} / \mathrm{m}^{3}\right)\end{array}$ & $\begin{array}{l}\text { Stone Powder } \\
\text { Content (\%) }\end{array}$ & $\begin{array}{c}\text { Water Absorption } \\
(\%)\end{array}$ \\
\hline Manufactured sand & 2.78 & 2730 & 1698 & 1923 & 7.45 & 0.25 \\
\hline River sand & 2.00 & 2597 & 1477 & 1641 & - & 0.15 \\
\hline
\end{tabular}

Table 4. Physical and mechanical properties of coarse aggregates.

\begin{tabular}{cccccc}
\hline \multirow{2}{*}{$\begin{array}{c}\text { Maximum Particle Size } \\
(\mathbf{m m})\end{array}$} & $\begin{array}{c}\text { Apparent Density } \\
\left(\mathbf{k g} / \mathbf{m}^{\mathbf{3}}\right)\end{array}$ & Pile-Up Density $\mathbf{( k g / \mathbf { m } ^ { \mathbf { 3 } } )}$ & \multicolumn{2}{c}{$\begin{array}{c}\text { Crushed Index } \\
(\mathbf{\%})\end{array}$} & $\begin{array}{c}\text { Content of } \\
\text { Needle-Pieces } \\
(\mathbf{\%})\end{array}$ \\
\cline { 3 - 4 } & 2770 & 1583 & 1682 & 7.2 & 4.70 \\
16 & 2766 & 1575 & 1662 & 9.6 & 4.54 \\
10 & 2711 & 1513 & 1575 & 16.8 & 1.32 \\
\hline
\end{tabular}

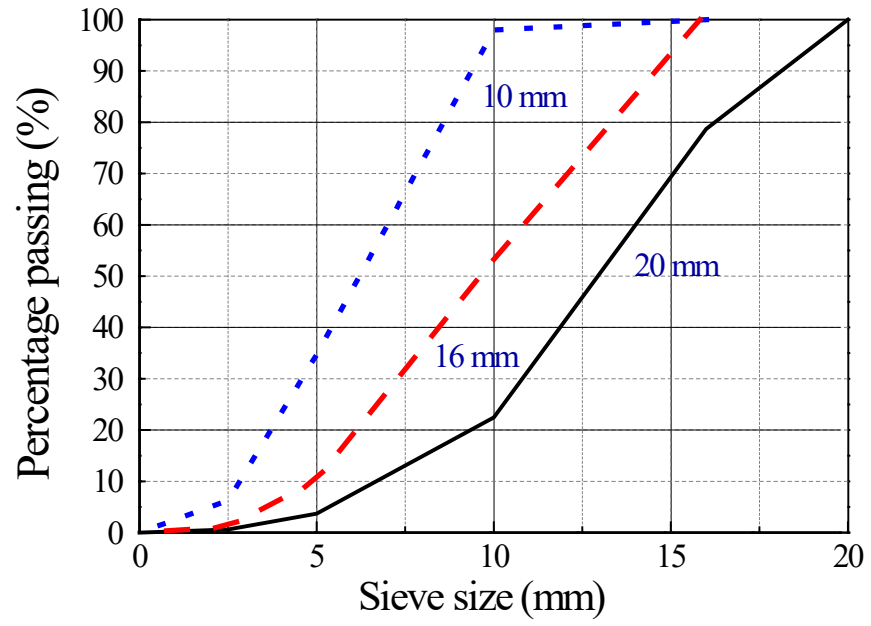

Figure 2. Particle size distribution of the coarse aggregate used. 


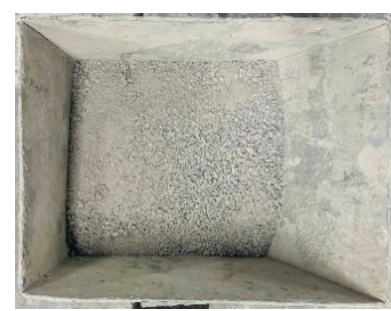

(a)

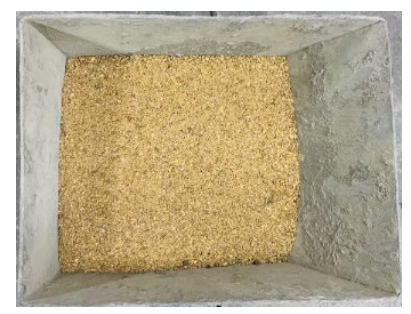

(b)

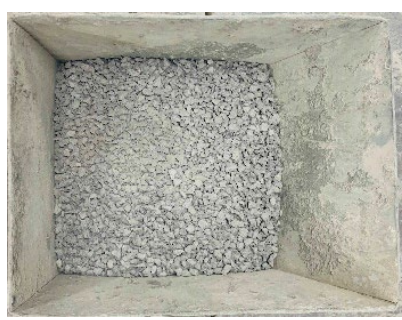

(c)

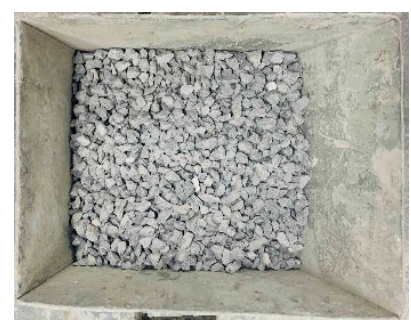

(d)

Figure 3. Pictures of aggregates: (a) manufactured sand; (b) river sand; (c) $5 \sim 10 \mathrm{~mm}$ aggregate; (d) 10 16 $\mathrm{mm}$ aggregate.

A polycarboxylate-based superplasticizer was used as a water reducer with a waterreducing rate of $29 \%$ and solid content of $23 \%$. The mixing water was tap water.

\subsection{Mix Proportion Design}

In this study, the absolute volume method is used to design the mix proportion of the SCC [31,32]. The target compressive strength of SCC was $69 \mathrm{MPa}$, which is standard for concrete of strength grade C60 with a guarantee rate of 95\%. The target workability of the fresh SCC was a slump larger than $260 \mathrm{~mm}$, a slump flow of $700 \mathrm{~mm}$, and a flow time $T_{500}$ less than $5 \mathrm{~s}$. The target pouring quality of the fresh SCC was a density greater than $2450 \mathrm{~kg} / \mathrm{m}^{3}$.

A total of 11 groups of mixtures for SCC were designed, with the influencing factors detailed in Table 5. The influencing factors included the ratio $R_{\mathrm{r}}$ of manufactured sand substituted by river sand, the ratios $R_{\mathrm{G}}$ and $R_{\mathrm{F}}$ of GGBS and fly ash in the total mass of the binders, and the maximum particle size of coarse aggregates (MPS). The water-to-binder ratio $w / b$ was kept at 0.31 , and the sand ratio $\beta_{\mathrm{s}}$ was kept constant at $50 \%$.

Table 5. The influencing factors designed in the mix proportion of the SCCs.

\begin{tabular}{|c|c|c|c|c|c|c|}
\hline No & $w / b$ & $\beta_{\mathrm{s}}(\%)$ & $R_{\mathrm{G}}(\%)$ & $R_{\mathrm{F}}(\%)$ & $R_{\mathrm{r}}(\%)$ & MPS (mm) \\
\hline R0 & \multirow{5}{*}{0.31} & \multirow{5}{*}{50} & \multirow{5}{*}{0} & \multirow{5}{*}{0} & 0 & \\
\hline $\mathrm{R} 27$ & & & & & 27.5 & \\
\hline R35 & & & & & 35 & 20 \\
\hline $\mathrm{R} 45$ & & & & & 45 & \\
\hline R100 & & & & & 100 & \\
\hline R35-F30 & \multirow{4}{*}{0.31} & \multirow{4}{*}{50} & 0 & 30 & \multirow{4}{*}{35} & \multirow{4}{*}{20} \\
\hline R35-G30 & & & 30 & 0 & & \\
\hline R35-G20F10 & & & 20 & 10 & & \\
\hline R35-G10F20 & & & 10 & 20 & & \\
\hline R35-C16 & \multirow{2}{*}{0.31} & \multirow{2}{*}{50} & \multirow{2}{*}{0} & \multirow[b]{2}{*}{0} & \multirow{2}{*}{35} & 16 \\
\hline R35-C10 & & & & & & 10 \\
\hline
\end{tabular}

The detailed mix proportions of the SCCs are presented in Table 6. The water content was $180 \mathrm{~kg} / \mathrm{m}^{3}$. The water reducer was kept constant at $1.6 \%$ of the total mass of the binders. This is to eliminate the influence of the water reducer content on the fresh performance of the SCC. 
Table 6. The detailed mix proportions of the SCCs $\left(\mathrm{kg} / \mathrm{m}^{3}\right)$.

\begin{tabular}{|c|c|c|c|c|c|c|c|c|c|c|}
\hline \multirow{2}{*}{ No } & \multirow{2}{*}{ Water } & \multirow{2}{*}{ Cement } & \multicolumn{2}{|c|}{ Mineral Admixture } & \multicolumn{3}{|c|}{ Coarse Aggregate } & \multicolumn{2}{|c|}{ Fine Aggregate } & \multirow{2}{*}{$\begin{array}{c}\text { Water } \\
\text { Reducer }\end{array}$} \\
\hline & & & GGBS & Fly Ash & $16 \sim 20$ & $10 \sim 16$ & $5 \sim 10$ & Manufactured Sand & River Sand & \\
\hline R0 & 180 & 581 & 0 & 0 & 247 & 206 & 370 & 822 & 0 & 9.29 \\
\hline $\mathrm{R} 27$ & 180 & 581 & 0 & 0 & 247 & 206 & 370 & 596 & 226 & 9.29 \\
\hline R35 & 180 & 581 & 0 & 0 & 247 & 206 & 370 & 534 & 288 & 9.29 \\
\hline R45 & 180 & 581 & 0 & 0 & 247 & 206 & 370 & 452 & 370 & 9.29 \\
\hline R100 & 180 & 581 & 0 & 0 & 247 & 206 & 370 & 0 & 822 & 9.29 \\
\hline R35-F30 & 180 & 406 & 0 & 174 & 247 & 206 & 370 & 534 & 288 & 9.29 \\
\hline R35-G30 & 180 & 406 & 174 & 0 & 247 & 206 & 370 & 534 & 288 & 9.29 \\
\hline R35-G20F10 & 180 & 406 & 116 & 58 & 247 & 206 & 370 & 534 & 288 & 9.29 \\
\hline R35-G10F20 & 180 & 406 & 58 & 116 & 247 & 206 & 370 & 534 & 288 & 9.29 \\
\hline R35-C16 & 180 & 581 & 0 & 0 & 0 & 294 & 528 & 534 & 288 & 9.29 \\
\hline R35-C10 & 180 & 581 & 0 & 0 & 0 & 0 & 822 & 534 & 288 & 9.29 \\
\hline
\end{tabular}

\section{Experimental Verification}

\subsection{Fresh Performance}

A horizontal shaft forced mixer with a maximum capacity of $100 \mathrm{~L}$ was used to mix the SCC. The slump, slump flow and slump flow time $T_{500}$ of the fresh SCC were tested immediately after mixing according to the Chinese code JGJ/T 283 [1], which is identical to ASTM C1611/C1611M [33]. The slump flow time $T_{500}$ is the time from the lifting of the slump cone to the diameter of the slump expansion surface reaching $500 \mathrm{~mm}$ [34]. Results with comparisons to target indices and specified filling ability are presented in Figure 4.

The reasonable mixing of machine-made sand and river sand can optimize the particle grading of sand and bring about good workability for fresh SCC [14,15]. In this test, the workability of SCC first decreased with the increasing ratio of river sand up to $27.5 \%$, then increased with the ratio of river sand from $27.5 \%$ to $45 \%$. This is similar to the study of pumped concrete with manufactured sand and river sand [17]. Compared with R0, R45 and R100, R27 has the worst fresh performance, with a smaller slump of $230 \mathrm{~mm}$, a lower slump flow of $600 \mathrm{~mm}$ and a longer flow time $T_{500}$ of $11 \mathrm{~s}$, while R35 has good fresh performance, with a suitable slump of $245 \mathrm{~mm}$, a higher slump flow of $700 \mathrm{~mm}$ and a shorter flow time $T_{500}$ of $3.5 \mathrm{~s}$.

Fly ash and GGBS are conducive to the slump and slump flow of fresh SCC R35-F30 and R35-G30 compared to R35. However, the addition of GGBS prolongs the $T_{500}$, while the addition of fly ash has no obvious influence on the $T_{500}$. The $T_{500}$ of R35-G30 is 1.43 times that of R35, while the $T_{500}$ of R35-G30 was equal to that of R35. Compared with R35-G30, R35-F30 had the same slump, a higher slump flow and a shorter $T_{500}$. This indicates that fly ash improved the working performance of the SCC. The reason is mainly due to the special morphological effects of fly ash, with microspheres featuring smooth surfaces, fine particle size and dense texture. Then, the fresh SCC with fly ash would adsorb a small amount of water in the mixing process [35], reducing the internal friction resistance and improving the flowability of the fresh concrete $[8,36]$.

Compared with R35, R35-G10F20 and R35-G20F10 presented with a higher slump and slump flow. This indicated that the hybrid fly ash and GGBS contributed to the improvement of flowability of SCC, although no superposition effect of fly ash and GGBS was observed in these indexes. However, the negative superposition effect of hybrid fly ash and GGBS appeared on the $T_{500}$. The $T_{500}$ of R35-G10F20 and R35-G20F10 were longer than both R35-F30 and R35-G30.

Compared with R35, R35-C16 had a better flowability, with a higher slump of $265 \mathrm{~mm}$, a higher slump flow of $720 \mathrm{~mm}$ and a flow time $T_{500}$ of $8.8 \mathrm{~s}$, while R35-C10 had a similar slump, a slightly lower slump flow and the longest $T_{500}$ of $11.3 \mathrm{~s}$. This indicates that the gradation of the coarse aggregates had effects on the slump and slump flow, and especially on the flow time of the fresh SCC. The $T_{500}$ of the SCC increased with the decreasing maximum particle size of the coarse aggregate. 


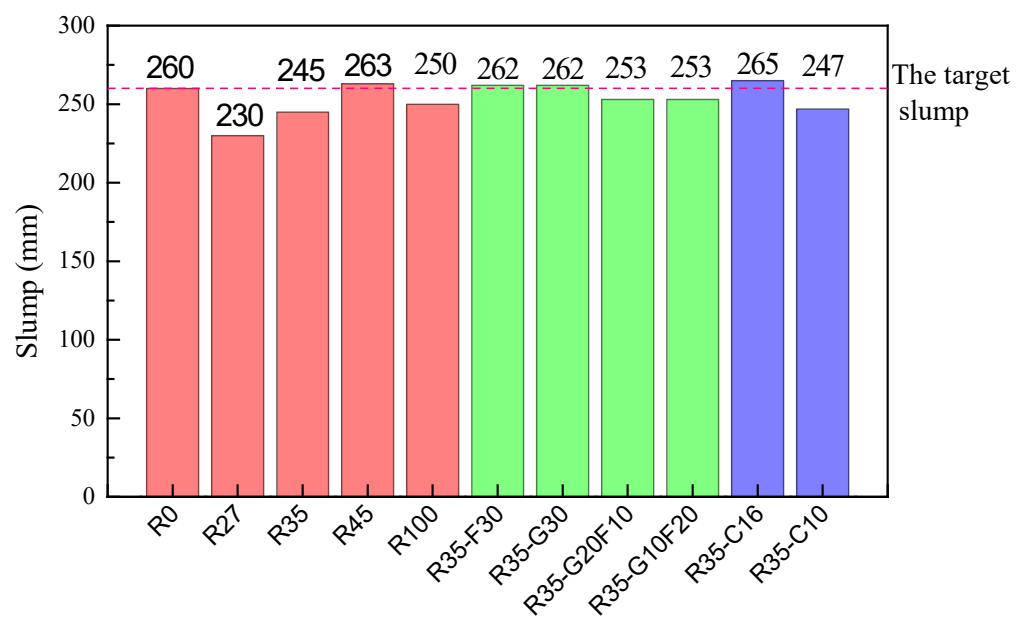

(a)

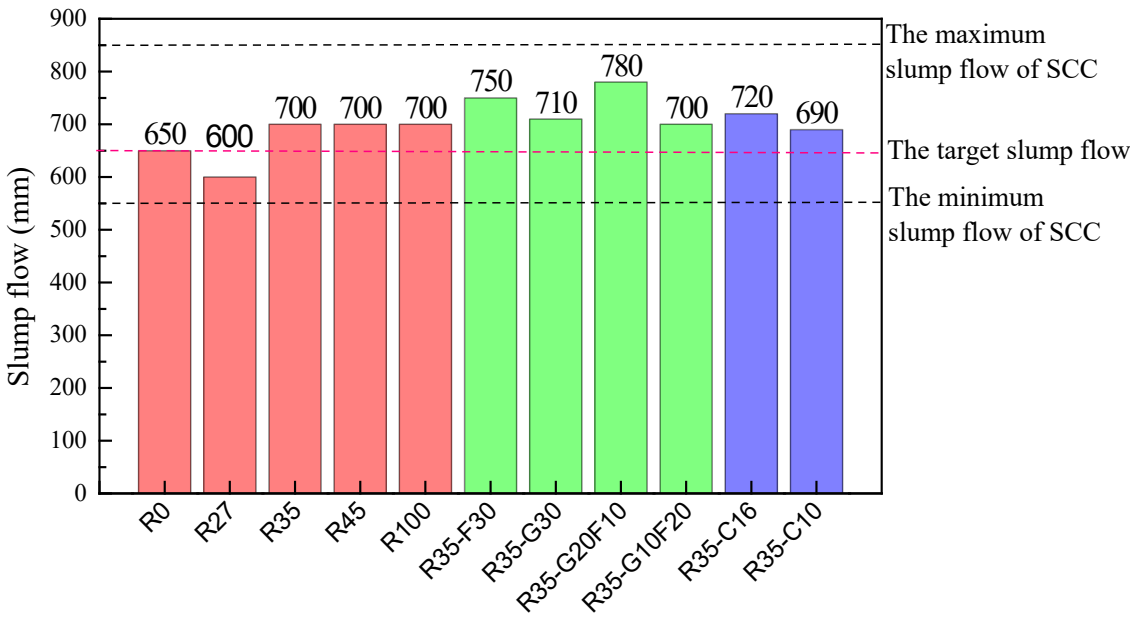

(b)

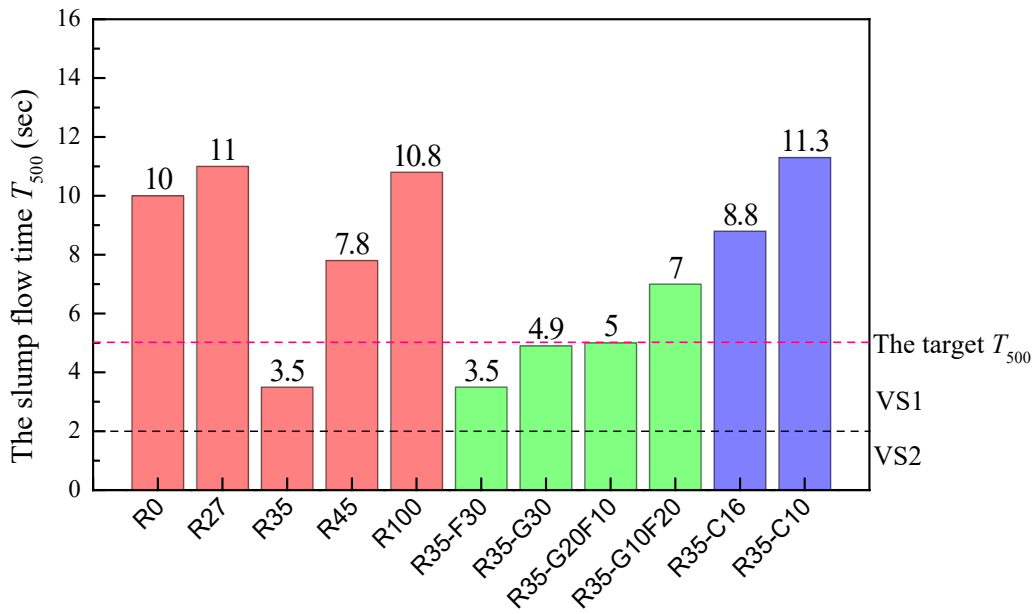

(c)

Figure 4. Workability of fresh SCC: (a) slump; (b) slump flow; (c) slump flow time $T_{500}$.

\subsection{The Density}

The density is an important index to present the self-compacting quality, which affects the performance of hardened SCC. Cubic specimens with dimensions of $150 \mathrm{~mm}$ were weighed after being cast for $24 \mathrm{~h}$. The densities of the SCCs were obtained from the weight divided by the volume of the cubic specimen. Results with a comparison of the target values are presented in Figure 5. 


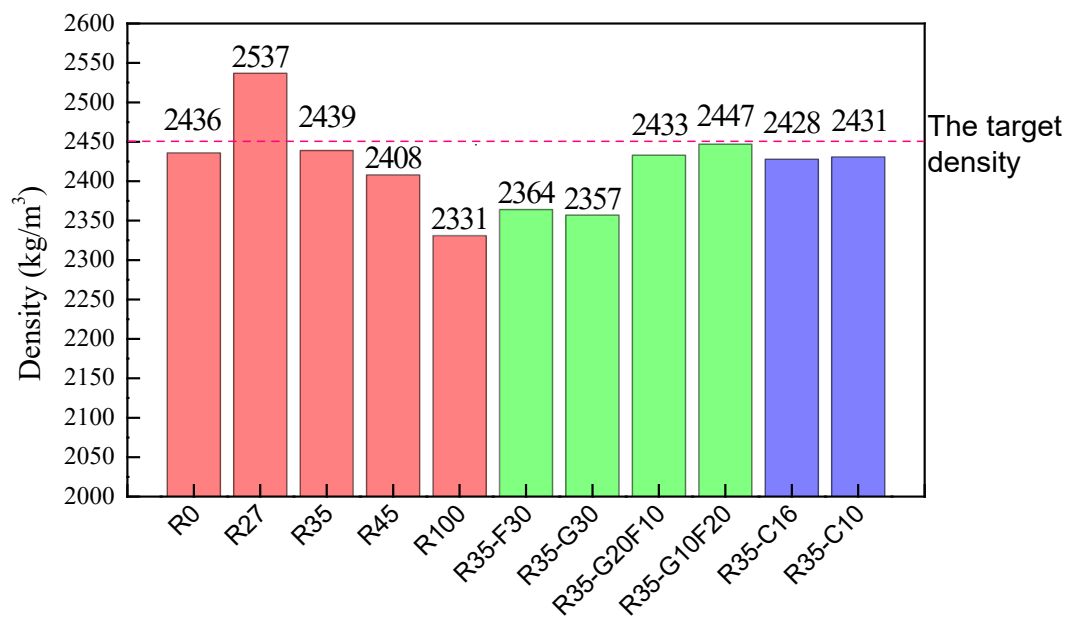

Figure 5. The densities of the SCCs.

Comparing R0 to R100, the SCC with manufactured sand had a density that was $4.5 \%$ higher than the SCC with river sand. This came from the lower density of river sand presented in Table 3. The mixing of manufactured sand and river sand in appropriate proportions could increase the density of SCC. The density of SCC first increased with the increasing ratio of river sand up to $27.5 \%$, then decreased with the ratio of river sand from $27.5 \%$ to $100 \%$. This indicates a hybrid effect of finer river sand to improve the particle grading of manufactured sand to promote the density of SCC. Compared with R0, R45 and R100, R27 had a maximum density of $2537 \mathrm{~kg} / \mathrm{m}^{3}$; R35 was next, with a density of $2439 \mathrm{~kg} / \mathrm{m}^{3}$.

Compared to R35, R35-F30 and R35-G30 had a density decrease of about 3\%. R35G10F20 and R35-G20F10, R35-C10 and R35-C16 had an almost equal density as R35. This indicates a slight decrease in the density of SCC with the single addition of fly ash and GGBS. The hybrid addition of GGBS and fly ash and the MPS of the coarse aggregate had no influence on the density of SCC.

\subsection{The Strength}

The cubic compressive strengths of the SCCs at a curing age of 28 days were tested in accordance with China code GB/T50081 [37], which is identical to British Standard BS EN 12390-3 [38]. Cubic specimens with dimensions of $150 \mathrm{~mm}$ were used. Three specimens were tested as a group. Results are presented in Figure 6.

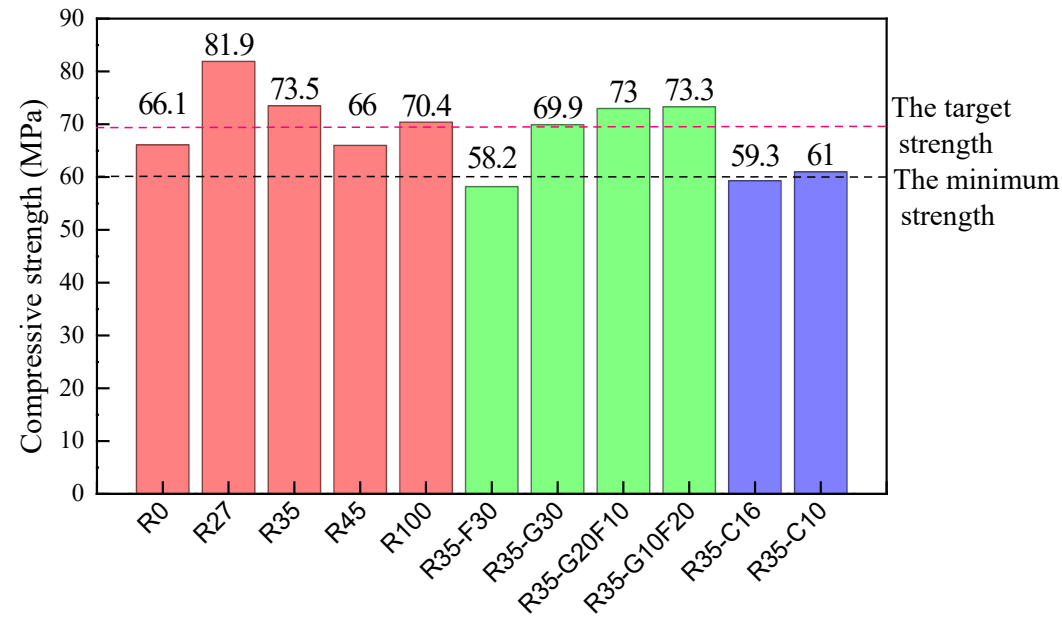

Figure 6. The cubic compressive strength of SCC. 
The substitution of manufactured sand with river sand could improve the cubic compressive strength of SCC. Except for R45, other SCCs with ratios of river sand of $27.5 \%$ and $35 \%$ had higher compressive strength; specifically, their compressive strength was increased by $23.9 \%$ and $11.2 \%$ compared to R0. Meanwhile, R100 had a higher cubic compressive strength, which was about $6.5 \%$ greater than R0. This indicates the good relationship of cubic compressive strength with the density of SCCs with hybrid sand. Manufactured sand is characterized by its rough surface, irregular particle shape, angular edges and the inevitable presence of stone powder, while river sand is characterized by smooth, round and small particles [39]. This different morphology between manufactured sand and river sand could influence the microstructure of SCCs to present their corresponding cubic compressive strengths.

The compressive strength of R35-F30 was only 79.0\% that of R35. This is due to the significant dilution effect of fly ash with a lower strength activity index of 84.3\% [40-42]. Comparatively, due to the strength activity index of GGBS, which reached $97.6 \%$, the compressive strength of R35-G30 was reduced only by $4.9 \%$ compared to R35. Meanwhile, R35-G10F20 and R35-G20F10 had similar compressive strengths to R35. This indicates that the hybrid of fly ash and GGBS had a positive superposition effect on the compressive strength of SCC [11,43].

The maximum particle size of the coarse aggregate had a significant effect on the compressive strength of the SCC. Compared to R35, with a maximum particle size of $20 \mathrm{~mm}$, the compressive strengths of R35-C16 and R35-C10, with maximum respective particle sizes of $16 \mathrm{~mm}$ and $10 \mathrm{~mm}$, were reduced by $19.3 \%$ and $17.0 \%$. This is similar to the compressive strength observed in conventional vibrated concrete [41]. Under the same mix proportion, the skeleton effect of coarse aggregates in concrete is weakened with decreasing MPS due to the lack of rationally closed packing among coarse aggregates with a similar particle size. At the same time, the decreased compressive strength was also related to the increased crushing index of smaller coarse aggregates, as presented in Table 4.

\section{Optimization by Grey Relational Analysis}

Grey relational analysis is a modern mathematics method for factor analysis in a system [26]. It is always used to evaluate the significance of factors in a given system and to judge the factors in order of importance. Its fundamental principle is evaluating the level of similarity for a data sequence by relevancy calculations. A greater relevancy means a higher similarity. In this paper, grey relational analysis is conducted based on the test results as the sample data to select the optimal mixtures from these eleven groups of SCC mixtures.

Assuming that the original data is $D$ in the sequence of slump, slump flow, $T_{500}$, density and cubic compressive strength, then,

$$
D=\left[\begin{array}{cccc}
d_{1}^{1} & d_{2}^{1} & \ldots & d_{n}^{1} \\
d_{1}^{2} & d_{2}^{2} & \ldots & d_{n}^{2} \\
\vdots & \vdots & & \vdots \\
d_{1}^{m} & d_{2}^{m} & \ldots & d_{n}^{m}
\end{array}\right]=\left[\begin{array}{ccccc}
260 & 650 & 10.0 & 2436 & 66.1 \\
230 & 600 & 11.0 & 2537 & 81.9 \\
245 & 700 & 3.5 & 2439 & 73.5 \\
263 & 700 & 7.8 & 2408 & 66.0 \\
250 & 700 & 10.8 & 2331 & 70.4 \\
262 & 750 & 3.5 & 2364 & 58.2 \\
262 & 710 & 4.9 & 2357 & 69.9 \\
253 & 780 & 5.0 & 2433 & 73.0 \\
253 & 700 & 7.0 & 2447 & 73.3 \\
265 & 720 & 8.8 & 2428 & 59.3 \\
247 & 690 & 11.3 & 2431 & 61.0
\end{array}\right]
$$

where $d_{k}{ }^{i}$ is the original data of the index $k$ at the solution $i . m=11$ and $n=5$ in this paper.

In this study, the slump, slump flow, and slump flow time $T_{500}$ are the dominant indicators for the workability of fresh SCC. The slump and slump flow are larger for better responses, while the slump flow time $T_{500}$ is smaller for a better response. The density 
and the compressive strength are the dominant responses for the hardened SCC, and they are larger for better responses. Thus, the standard matrix $C$ can be obtained with the standardizing Equations (2)-(4),

$$
\begin{gathered}
C_{k}^{i}=\frac{d_{k}^{i}-\min \left(d_{k^{\prime}}^{i}, i=1,2, \ldots . m\right)}{\max \left(d_{k^{\prime}}^{i}=1,2, \ldots m\right)-\min \left(d_{k^{\prime}}^{i}, i=1,2, \ldots m\right)} \text { (for the larger and better response) } \\
C_{k}^{i}=\frac{\max \left(d_{k^{\prime}}^{i}, i=1,2, \ldots m\right)-d_{k}^{i}}{\max \left(d_{k^{\prime}}^{i}, i=1,2, \ldots m\right)-\min \left(d_{k^{\prime}}^{i}, i=1,2, \ldots m\right)}(\text { for the smaller and better response) } \\
C=\left[\begin{array}{cccccccc}
C_{1}^{1} & C_{2}^{1} & \ldots & C_{5}^{1} \\
C_{1}^{2} & C_{2}^{2} & \ldots & C_{5}^{2} \\
\vdots & \vdots & & \vdots \\
C_{1}^{11} & C_{2}^{11} & \ldots & C_{5}^{11}
\end{array}\right]=\left[\begin{array}{cccccc}
0.8571 & 0.2778 & 0.1667 & 0.5097 & 0.3333 \\
0.0000 & 0.0000 & 0.0385 & 1.0000 & 1.0000 \\
0.4286 & 0.5556 & 1.0000 & 0.5243 & 0.6456 \\
0.9429 & 0.5556 & 0.4487 & 0.3738 & 0.3291 \\
0.5714 & 0.5556 & 0.0641 & 0.0000 & 0.5148 \\
0.9143 & 0.8333 & 1.0000 & 0.1602 & 0.0000 \\
0.9143 & 0.6111 & 0.8205 & 0.1262 & 0.4937 \\
0.6571 & 1.0000 & 0.8077 & 0.4951 & 0.6245 \\
0.6571 & 0.5556 & 0.4943 & 0.5631 & 0.6371 \\
1.0000 & 0.6667 & 0.3205 & 0.4709 & 0.0464 \\
0.4857 & 0.5000 & 0.0000 & 0.4854 & 0.1181
\end{array}\right]
\end{gathered}
$$

where $C^{*}$ is the referenced sequence.

$$
C^{*}=\left[C_{1}{ }^{*}, C_{2}{ }^{*}, \ldots, C_{5}^{*}\right]=\left[\begin{array}{lllll}
1.0000 & 1.0000 & 1.0000 & 1.0000 & 1.0000
\end{array}\right]
$$

The matrix $C$ is the compared sequence, and the correlation coefficient $\xi_{j}(i)$ is obtained from Equation (6)

$$
\xi_{j}(i)=\frac{\operatorname{minmin}_{i}\left|C_{i}^{*}-C_{i}^{j}\right|+\underset{j}{\max \max _{i}}\left|C_{i}^{*}-C_{i}^{j}\right|}{\left|C_{i}^{*}-C_{i}^{j}\right|+\rho \operatorname{maxmax}_{i}\left|C_{i}^{*}-C_{i}^{j}\right|}
$$

where the value range of $\rho$ is $[0,1]$, and generally takes the form of $\rho=0.5$.

Then, the evaluation matrix of indexes $E$ is shown as follows.

$$
E=\left[\begin{array}{cccc}
\xi_{1}(1) & \xi_{1}(2) & \ldots & \xi_{1}(5) \\
\xi_{2}(1) & \xi_{2}(2) & \ldots & \xi_{2}(5) \\
\vdots & \vdots & & \vdots \\
\xi_{11}(1) & \xi_{11}(2) & \ldots & \xi_{11}(5)
\end{array}\right]=\left[\begin{array}{ccccc}
0.7777 & 0.4091 & 0.3750 & 0.5049 & 0.4286 \\
0.3333 & 0.3333 & 0.3421 & 1.0000 & 1.0000 \\
0.4667 & 0.5294 & 1.0000 & 0.5125 & 0.5852 \\
0.8975 & 0.5294 & 0.4756 & 0.4440 & 0.4270 \\
0.5384 & 0.5294 & 0.3482 & 0.3333 & 0.5075 \\
0.8537 & 0.7500 & 1.0000 & 0.3732 & 0.3333 \\
0.8537 & 0.5625 & 0.7358 & 0.3640 & 0.4969 \\
0.5932 & 1.0000 & 0.7222 & 0.4976 & 0.5711 \\
0.5932 & 0.5294 & 0.4972 & 0.5337 & 0.5794 \\
1.0000 & 0.6000 & 0.4239 & 0.4859 & 0.3440 \\
0.4930 & 0.5000 & 0.3333 & 0.4928 & 0.3618
\end{array}\right]
$$

We can then determine the entropy weight for the index $i$ by assuming the number of indexes and evaluation objects are $n=5$ and $m=11$, respectively:

$$
f_{i j}=\frac{\xi_{j}(i)}{\sum_{j=1}^{m} \xi_{j}(i)}
$$


Thus,

$$
F=\left[\begin{array}{cccc}
f_{11} & f_{12} & \ldots & f_{1 n} \\
f_{21} & f_{22} & \ldots & f_{2 n} \\
\vdots & \vdots & & \vdots \\
f_{m 1} & f_{m 2} & \ldots & f_{m n}
\end{array}\right]=\left[\begin{array}{ccccc}
0.105 & 0.065 & 0.060 & 0.091 & 0.076 \\
0.045 & 0.053 & 0.055 & 0.180 & 0.177 \\
0.063 & 0.084 & 0.160 & 0.092 & 0.104 \\
0.121 & 0.084 & 0.076 & 0.080 & 0.076 \\
0.073 & 0.084 & 0.056 & 0.060 & 0.090 \\
0.115 & 0.120 & 0.160 & 0.067 & 0.059 \\
0.115 & 0.090 & 0.118 & 0.066 & 0.088 \\
0.080 & 0.159 & 0.115 & 0.090 & 0.101 \\
0.080 & 0.084 & 0.080 & 0.096 & 0.103 \\
0.135 & 0.096 & 0.068 & 0.088 & 0.061 \\
0.067 & 0.080 & 0.053 & 0.089 & 0.064
\end{array}\right]
$$

The entropy $h_{\mathrm{i}}$ of the index $i$ is shown as

$$
h_{i}=-k \sum_{j=1}^{11} f_{i j} \ln f_{i j}
$$

where $k=1 / \ln \mathrm{m}=1 / \ln 11=0.417$.

Thus,

$$
\begin{gathered}
\mathrm{H}=\left[h_{1}, h_{2}, \ldots, h_{5}\right] \\
=[0.98044,0.98323,0.96412,0.97988,0.97778]
\end{gathered}
$$

The entropy weight for the index $i$ is

$$
\omega_{i}=\frac{1-h_{i}}{n-\sum_{1}^{n} h_{i}}\left(0 \leq \omega_{i} \leq 1, \sum_{i=1}^{n} \omega_{i}=1\right)
$$

The entropy weight matrix of various indexes is

$$
\begin{gathered}
W=\left[\omega_{1}, \omega_{2}, \ldots, \omega_{5}\right] \\
=[0.17076,0.14638,0.31319,0.17567,0.19400]
\end{gathered}
$$

Therefore, the comprehensive evaluation index is

$$
\begin{gathered}
R=E \times W^{T} \\
=[0.48197,0.58253,0.67393,0.54055,0.43551,0.69897,0.61890,0.67207, \\
0.54066,0.54344,0.41853]
\end{gathered}
$$

This means the sequence is R35-F30, R35, R35-G20F10, R35-G30, R27, R35-C16, R35G10F20, R45, R0, R100, and R35-C10. The mixtures of R35-F30, R35 and R35-G20F10 are the relatively better groups of the eleven mixtures.

\section{Discussion}

Based on the test results of eleven SCCs in this study, their workability meets the requirements to be labeled as self-compacting. The SCCs marked as R27, R35, R100, R35G30, R35-G20F10 and R35-G10F20 meet the target compressive strength of the SCC. Due to the complex influences of the properties and contents of raw materials, including fly ash, GGBS, manufactured sand, river sand and coarse aggregate, different optimal mixtures can be obtained by considering the performance. Considering the slump and the slump flow of fresh SCC, the mixtures R0, R45, R35-F30, R35-G30 and R35-C16 are optimal. Considering the flow time $T_{500}$ of fresh SCC, the mixtures R35, R35-F30 and R35-G20F10 are optimal. Considering the density of SCC, the mixtures R0, R27, R35 and R35-G10F20 are optimal. Considering the compressive strength of SCC, the mixtures R27, R35, R100, R35-G30, R35-G20F10 and R35-G10F20 are optimal. 
Therefore, it is difficult to determine the optimal mixture of SCC only by the test results to satisfy all aspects of performance. In this condition, grey relational analysis is used to obtain the optimal solution among these eleven SCC mixtures after comprehensively considering the workability, density and mechanical properties of the SCCs. As a result, R35-F30, R35 and R35-G20F10 are the better of the eleven mixtures. This agrees well with the experimental results. R35-F30 has a fresh performance with a high slump of $262 \mathrm{~mm}$, a high slump flow of $750 \mathrm{~mm}$ and a short flow time $T_{500}$ of $3.5 \mathrm{~s}$, a density of $2364 \mathrm{~kg} / \mathrm{m}^{3}$, and a compressive strength of 58.2 MPa. R35 has a fresh performance with a suitable slump of $245 \mathrm{~mm}$, a high slump flow of $700 \mathrm{~mm}$ and a short flow time $T_{500}$ of $3.5 \mathrm{~s}$, a density of 2439 $\mathrm{kg} / \mathrm{m}^{3}$, and a high compressive strength of 73.5 MPa. R35-G20F10 has a fresh performance with a high slump of $253 \mathrm{~mm}$, a high slump flow of $780 \mathrm{~mm}$, a short flow time T500 of $5 \mathrm{~s}$, and a density of $2433 \mathrm{~kg} / \mathrm{m} 3$ and a high compressive strength of $73.0 \mathrm{MPa}$.

Given all of the above, the experimental study is suitable for comparing the effects of the raw materials on one aspect of the performance of SCCs, such as workability, density or compressive strength. The grey relational analysis used in this study is applicable to further optimize the mix proportion of SCCs while considering the comprehensive performance of the SCC.

\section{Conclusions}

Based on the absolute volume method of mix proportion design of SCC, eleven groups of SCCs were designed with changes in the content of fly ash and GGBS, the content of manufactured sand and river sand, and the maximum particle sizes of coarse aggregates. The design was verified by experimental studies and evaluated by grey relational analysis. Conclusions can be drawn as follows.

The replacement of manufactured sand by a certain amount of river sand could improve the flowability of fresh SCC and increase the compressive strength of hardened SCC. Both the GGBS and fly ash are beneficial for the slump and slump flow of fresh SCC; however, they also increase the flow time. The hybrid effect of GGBS with fly ash would improve the workability of SCC with equal compressive strength. The maximum particle size of the coarse aggregate significantly influenced the performance of the SCC. Compared to an SCC with a maximum coarse aggregate particle size of $20 \mathrm{~mm}$, an SCC with a maximum coarse aggregate particle size of $16 \mathrm{~mm}$ demonstrated more favorable workability, but the cubic compressive strength of SCC decreased by nearly $20 \%$.

Based on the test results, a grey correlation analysis model was built. Combined with the entropy evaluation method, the optimal mixtures of SCC were selected from these eleven group mixtures. The optimal mixture considering the workability of fresh SCC was found to be R35-F30, which demonstrated fresh performance with a slump of 265 $\mathrm{mm}$, a slump flow of $750 \mathrm{~mm}$ and a flow time $T_{500}$ of $3.5 \mathrm{~s}$. The optimal mixture when comprehensively considering the workability and mechanical properties of SCC was found to be R35, which demonstrated fresh performance with a slump of $245 \mathrm{~mm}$, a slump flow of $700 \mathrm{~mm}$, a flow time $T_{500}$ of $3.5 \mathrm{~s}$, a density of $2439 \mathrm{~kg} / \mathrm{m}^{3}$ and a compressive strength of $73.5 \mathrm{MPa}$. This method has improved the objectivity of the evaluation and avoided the loss of information which can be used for the optimization of mix proportions of SCC.

Author Contributions: Conceptualization and methodology, X.D. and M.Z.; validation, X.D. and X.Q.; formal analysis, X.Q. and M.Z.; investigation, Y.W. and M.Z.; data curation, Y.R. and M.Z.; writing-original draft preparation, X.D. and Y.W; writing-review and editing, Y.R., M.Z. and X.D; funding acquisition, X.D. All authors have read and agreed to the published version of the manuscript.

Funding: This research was funded by the Natural Science Foundation of Henan, China, grant number "212300410192"; Key Scientific and Technological Research Project of University in Henan, China, grant number "20A560015".

Institutional Review Board Statement: Not applicable.

Informed Consent Statement: Not applicable. 
Data Availability Statement: The data presented in this study are available in the submitted article.

Conflicts of Interest: The authors declare no conflict of interest.

\section{References}

1. Ministry of Housing and Urban-Rural Development of the People's Republic of China. Technical Specification for Application of Self-Compacting Concrete; JGJ/T 283-2012; China Building Industry Press: Beijing, China, 2012.

2. Ding, X.; Li, C.; Zhao, M.; Li, J.; Geng, H.; Lian, L. Tensile strength of self-compacting steel fiber reinforced concrete evaluated by different test methods. Crystals 2021, 11, 251. [CrossRef]

3. Siamardi, K. Optimization of fresh and hardened properties of structural light weight self-compacting concrete mix design using response surface methodology. Constr. Build. Mater. 2022, 317, 125928. [CrossRef]

4. Singh, N.; Kumar, P.; Goyal, P. Reviewing the behaviour of high volume fly ash based self compacting concrete. J. Build. Eng. 2019, 26, 100882. [CrossRef]

5. de la Rosa, Á.; Poveda, E.; Ruiz, G.; Cifuentes, H. Proportioning of self-compacting steel-fiber reinforced concrete mixes based on target plastic viscosity and compressive strength: Mix-design procedure \& experimental validation. Constr. Build. Mater. 2018, 189, 409-419.

6. Beygi, M.H.; Kazemi, M.T.; Amiri, J.V.; Nikbin, I.M.; Rabbanifar, S.; Rahmani, E. Evaluation of the effect of maximum aggregate size on fracture behavior of self compacting concrete. Constr. Build. Mater. 2014, 55, 202-211. [CrossRef]

7. Sua-Iam, G.; Chatveera, B. A study on workability and mechanical properties of eco-sustainable self-compacting concrete incorporating PCB waste and fly ash. J. Clean. Prod. 2021, 329, 129523. [CrossRef]

8. Khan, M.; Ali, M. Improvement in concrete behavior with fly ash, silica-fume and coconut fibres. Constr. Build. Mater. 2019, 203, 174-187. [CrossRef]

9. Li, C.; Geng, H.; Zhou, S.; Dai, M.; Sun, B.; Li, F. Experimental Study on Preparation and Performance of Concrete with Large Content of Fly Ash. Front. Mater. 2022, 8, 764820. [CrossRef]

10. Al-Oran, A.A.A.; Safiee, N.A.; Nasir, N.A.M. Fresh and hardened properties of self-compacting concrete using metakaolin and GGBS as cement replacement. Eur. J. Environ. Civ. Eng. 2019, 26, 1-14. [CrossRef]

11. Dinakar, P.; Sethy, K.P.; Sahoo, U.C. Design of self-compacting concrete with ground granulated blast furnace slag. Mater. Des. 2013, 43, 161-169. [CrossRef]

12. Tadi, C.; Rao, T.C. Investigating the performance of self-compacting concrete pavement containing GGBS. Mater. Today Proc. 2022, 49, 2013-2018. [CrossRef]

13. Qiu, C.Y.; Yu, F. Research on plastic shrinkage cracking of self-compacting concrete based on orthogonal experiment. Water Resour. Power 2021, 39, 155-160.

14. Nikbin, I.; Beygi, M.; Kazemi, M.; Amiri, J.V.; Rahmani, E.; Rabbanifar, S.; Eslami, M. A comprehensive investigation into the effect of aging and coarse aggregate size and volume on mechanical properties of self-compacting concrete. Mater. Des. 2014, 59, 199-210. [CrossRef]

15. Ding, X.; Li, C.; Xu, Y.; Li, F.; Zhao, S. Experimental study on long-term compressive strength of concrete with manufactured sand. Constr. Build. Mater. 2016, 108, 67-73. [CrossRef]

16. Hou, W.-Q.; Yang, J.-J.; Zhang, Z.-X.; Yuan, X.-Q. Experimental study and application of manufactured sand self-compacting concrete in concrete-filled-steel-tube arch bridge: A case study. Case Stud. Constr. Mater. 2021, 15, e00718. [CrossRef]

17. Zhang, L. Experimental research of machine-made sand content on performance impact of mixing pump concrete. Shanxi Sci. Technol. Commun. 2016, 2, 84-86.

18. Sargam, Y.; Faytarouni, M.; Riding, K.; Wang, K.; Jahren, C.; Shen, J. Predicting thermal performance of a mass concrete foundation-A field monitoring case study. Case. Stud. Constr. Mater. 2019, 11, e00289. [CrossRef]

19. Ahangari, K.; Beygi, M.H.A.; Rezaei, Y. Applicability of fiber reinforced self-compacting concrete for tunnel lining. Arab. J. Geosci. 2013, 6, 3841-3846. [CrossRef]

20. Craeye, B.; Van Itterbeeck, P.; Desnerck, P.; Boel, V.; De Schutter, G. Modulus of elasticity and tensile strength of self-compacting concrete: Survey of experimental data and structural design codes. Cem. Concr. Compos. 2014, 54, 53-61. [CrossRef]

21. Asteris, P.G.; Kolovos, K. Self-compacting concrete strength prediction using surrogate models. Neural Comput. Appl. 2019, 31, 409-424. [CrossRef]

22. Deeb, R.; Kulasegaram, S.; Karihaloo, B.L. 3D modelling of the flow of self-compacting concrete with or without steel fibres. Part I: Slump flow test. Comput. Part Mech. 2014, 1, 373-389. [CrossRef]

23. Suji, D.; Adesina, A.; Mirdula, R. Optimization of self-compacting composite composition using Taguchi-Grey relational analysis. Materialia 2021, 15, 101027. [CrossRef]

24. Chang, C.Y.; Huang, R.; Lee, P.C.; Weng, T.L. Application of a weighted Grey-Taguchi method for optimizing recycled ag-gregate concrete mixtures. Cem. Concr. Comp. 2011, 33, 1038-1049. [CrossRef]

25. Zhu, L.; Zhao, C.; Dai, J. Prediction of compressive strength of recycled aggregate concrete based on gray correlation analysis. Constr. Build. Mater. 2021, 273, 121750. [CrossRef]

26. Deng, J. Multidimensional Grey Planning; Huazhong University Press: Wuhan, China, 1989. 
27. The State Bureau of Quality and Technical Supervision of the People's Republic of China. Common Portland Cement; GB175-2007; China Standard Press: Beijing, China, 2008.

28. Ministry of Housing and Urban-Rural Development of the People's Republic of China. Technical Code for Application of Mineral Admixture; GB/T 51003-2014; China Building Industry Press: Beijing, China, 2014.

29. General Administration of Quality Supervision, Inspection and Quarantine of the People's Republic of China. Sand for Construction; GB/T 14684-2011; China Standard Press: Beijing, China, 2011.

30. General Administration of Quality Supervision, Inspection and Quarantine of the People's Republic of China. Pebble and Crushed Stone for Construction; GB/T 14685-2011; China Standard Press: Beijing, China, 2011.

31. Ding, X.; Li, C.; Han, B.; Lu, Y.; Zhao, S. Effects of different deformed steel-fibers on preparation and fundamental properties of self-compacting SFRC. Constr. Build. Mater. 2018, 168, 471-481. [CrossRef]

32. Zhao, M.; Ding, X.; Li, J.; Law, D. Numerical Analysis of Mix Proportion of Self-Compacting Concrete Compared to Ordinary Concrete. Key Eng. Mater. 2019, 789, 69-75. [CrossRef]

33. ASTM. International, Standard Test Method for Slump Flow of Self-Consolidating Concrete; ASTM C1611/C1611M; ASTM: West Conshohocken, PA, USA, 2009.

34. Ding, X.; Geng, H.; Shi, K.; Song, L.; Li, S.; Liu, G. Study on Adaptability of Test Methods for Workability of Fresh Self-Compacting SFRC. Materials 2021, 14, 5312. [CrossRef]

35. Kurda, R.; de Brito, J.; Silvestre, J.D. Influence of recycled aggregates and high contents of fly ash on concrete fresh properties. Cem. Concr. Compos. 2017, 84, 198-213. [CrossRef]

36. Akid, A.S.M.; Hossain, S.; Munshi, M.I.U.; Elahi, M.M.A.; Sobuz, M.H.R.; Tam, V.W.Y.; Islam, M.S. Assessing the influence of fly ash and polypropylene fiber on fresh, mechanical and durability properties of concrete. J. King. Saud. Univ Eng. Sci. 2021; in press. [CrossRef]

37. Ministry of Housing and Urban-Rural Development of the People's Republic of China. Standard for Test Methods of Concrete Physical and Mechanical Properties; GB/T50081-2019; China Building Industry Press: Beijing, China, 2019.

38. European Committee for Standardization. Testing Hardened Concrete—Compressive Strength of Test Specimens; BS EN 12390-3-2009; European Committee for Standardization: London, UK, 2009.

39. Zhao, S.; Ding, X.; Zhao, M.; Li, C.; Pei, S. Experimental study on tensile strength development of concrete with manufactured sand. Constr. Build. Mater. 2017, 138, 247-253. [CrossRef]

40. Ding, X.X.; Lu, Y.Z.; Zhao, M.S.; Chen, M.H.; Zhao, S.B. Experimental study on tensile properties of high-performance concrete with machine-made sand and fly-ash. WIT Trans. Eng. Sci. 2015, 164-172.

41. Ding, X.X.; Lu, Y.Z.; Zhao, M.S.; Chen, M.H.; Zhao, S.B. Influence coefficient of fly-ash for determination of binder's compres-sive strength in mix proportion design of concrete. WIT Trans. Eng. Sci. 2015, 115-123.

42. Liu, S.; Zhu, M.; Ding, X.; Ren, Z.; Zhao, S.; Zhao, M.; Dang, J. High-Durability Concrete with Supplementary Cementitious Admixtures Used in Corrosive Environments. Crystals 2021, 11, 196. [CrossRef]

43. Yang, F.L.; Ji, Y.H.; Liu, W.; Zhang, C.S.; Fang, D.Y. Experimental study on ultra-high-performance concrete with coarse aggregate. Concrete 2018, 12, 110-113. 